\title{
The Management of Cervical Spine Injuries - A Literature Review
}

\section{Isaac Okereke (D) \\ Kingsley Mmerem \\ Dhanasekaraprabu \\ Balasubramanian}

Department of Trauma \& Orthopaedics, The Royal London Hospital, London, UK
Abstract: Due to the inherent bony instability of the cervical spine, there is an over-reliance on ligamentous structures for stability, making this segment of the vertebral column most prone to traumatic injuries. The frequently occurring mechanisms of injury include axial compression, hyper-flexion, hyper-extension, and rotational type injuries. Good pre-hospital care and a thorough assessment in the emergency department of patients suspected to have a cervical spine injury (CSI) leads to improved clinical outcomes. The objective of the initial evaluation of a patient with a suspected CSI is to identify the presence of injuries through thorough clinical and radiologic assessments as missed injuries are potentially catastrophic. The treatment of cervical spine injuries can be conservative, pharmacological, or surgical, and aims to halt SCI progression, stabilize the spine, and to allow rehabilitation of the patient.

Keywords: cervical spine injury, spinal immobilization, spinal decompression, cervical spine assessment

\section{Introduction}

The cervical spine consists of seven very specialized vertebrae located between the skull proximally and the thoracic vertebrae distally, articulating at the craniocervical joint and with the first thoracic vertebra respectively. The cervical spine supports the head and its movements, protects the spinal cord, and is a conduit for the vascular supply to the brain through the foramen transversarium located laterally in C3 to C7 vertebrae.

Due to the inherent bony instability of the cervical spine, there is an overreliance on ligamentous structures for stability making this segment of the vertebral column most prone to injuries. For example, the subaxial cervical spine relies on static stabilizers like the anterior longitudinal ligament, the posterior longitudinal ligament, facet joint capsules, intervertebral discs, the interspinous and supraspinous ligaments to maintain stability while providing maximum flexibility. ${ }^{1}$

It is estimated that approximately 1000 people sustain a spinal cord injury (SCI) every year in the $\mathrm{UK}^{2}$ with cervical spine injuries (CSI) accounting for a significant proportion of these injuries. There are 10,000 to 12,000 new SCIs every year in the US with two-thirds of the patients aged less than 30 . In a review of 65 studies, Milby et al found the prevalence of CSI in all trauma patients to be $3.7 \%$. In this study, alert patients had a CSI prevalence of $2.8 \%$, while clinically unevaluable patients had a significantly higher prevalence rate of $7.7 \% .^{3}$ The majority of CSI is
Correspondence: Isaac Okereke Department of Trauma \& Orthopaedics, The Royal London Hospital, UK Tel +447405742716

Email okereke.isaac@gmail.com 
seen between the ages of 15 and 30 , and in those older than $65 .{ }^{4,5}$ In a retrospective ten-year multicentre analysis of CSI in the southeast of Nigeria, Uche et al found a male to female distribution of 3.1:1 in the study cohort. ${ }^{6}$ Motor vehicle accidents, fall from height, sports-related injuries and assault are the most common causes of CSI in the younger population. ${ }^{7}$ In the elderly, non-traumatic causes of cervical spine injuries that may be due to osteoporotic compression fractures, degenerative diseases of the spine or compression fractures from spinal tumours are more prevalent. The $\mathrm{C} 5 / \mathrm{C} 6$ and $\mathrm{C} 6 / \mathrm{C} 7$ are the most frequently injured cervical vertebrae following trauma, followed by the $\mathrm{C} 1 / \mathrm{C} 2$ vertebrae. The common mechanisms of injury are axial compression causing Jefferson-type fractures in $\mathrm{C} 1$ vertebrae, occipito-condylar fractures or burst fractures in other vertebrae; hyper-flexion, hyper-extension, and rotational-type injuries. ${ }^{8}$

\section{Initial Assessment and Evaluation Cervical Spine Clearance}

The aim of the initial assessment of a patient with a suspected CSI is to "clear the cervical spine". The objective of cervical spine clearance is to establish the absence of an injury to the spine and to identify any injuries, where present, that might require ongoing treatment with a collar or a surgical intervention.

The ATLS ${ }^{\circledR}$ protocol should be followed in the initial clinical assessment of trauma patients suspected to have a CSI with sufficient attention paid to other limb or lifethreatening distracting injuries. The British Orthopaedic Association Standards for Trauma and Orthopaedics (BOAST) guidelines for spinal clearance in a trauma patient recommend that all patients involved in significant blunt trauma are assumed to have an unstable injury to their spine. ${ }^{8,9}$ The proper management of patients suspected to have suffered a CSI begins in the field. Excessive movements of the spine by untrained and overzealous first-responders in the setting of an unstable spinal injury is one of the most common cause of a secondary CSI. ${ }^{10}$ Spinal precautions should therefore be instituted straightaway in the pre-hospital setting to immobilize the cervical spine and minimize neck movements during the movement of patients in line with the British National Institute for Health and Care Excellence (NICE) guidelines. ${ }^{2}$ Current evidence supports the utilization of the triad of a cervical collar, a spine board, and head immobilization between a pair of sandbags or foam wedges. This enables full in-line spinal immobilization and adequately minimizes head motion or rotation during the transfer of patients in the pre-hospital setting and during initial assessment in hospital. ${ }^{11,12}$ It should be noted that spine boards are very hard surfaces designed primarily to resist spine motion, therefore, when they are utilized patients should be immediately transferred to a softer mattress as soon as possible to prevent the occurrence of pressure ulcers. ${ }^{13,14}$

All patients should have a neurologic assessment using the International Standards for Neurological Classification of Spinal Cord Injury (ISNCSCI) impairment scale, pretransfer, post-transfer, and pre- and post-operatively. ${ }^{15}$ The American Spinal Injuries Association (ASIA) grading (see Figure 1), a modification of the Frankel scoring system, is a universal classification tool for spinal cord injuries based on a standardized sensory and motor assessment. ${ }^{16,17}$ It is used to determine the sensory and motor level of injury for each side of the body and whether the injury is complete or incomplete. Scores are recorded on a scale of A to E: $\mathrm{A}$ is a complete spine injury, and $\mathrm{E}$ a normal neurological examination finding.

Clinical examination has been shown to have a low sensitivity in identifying CSI, however, the presence of tenderness on palpation along the spinous processes of the first cervical vertebrae to the first thoracic vertebrae and across the facet joints, a gap or step deformity in the continuity of the cervical structures, the presence of a haematoma or oedema around these structures is indicative of an acute injury. ${ }^{18}$ Also, a spinal cord injury should be suspected in obtunded patients, in patients with neck pain, and in those with evidence of a neurological injury.

The decision to image is taken following either the National Emergency X-Radiography Utilization Study Group (NEXUS) guidelines or the Canadian C-Spine Rule (CCR) in alert and stable patients. The NEXUS guidelines suggest cervical spine radiography is unnecessary if the patient satisfy all of the following five low-risk criteria: the absence of midline tenderness, normal level of alertness, no evidence of intoxication, no abnormal neurological findings, and no painful distracting injuries. ${ }^{19}$ In a large cohort of patients with CSI, plain film views such as anteroposterior AP, crosstable lateral and open-mouth odontoid views missed $61 \%$ of all fractures, $36 \%$ of subluxations and dislocations and gave false-negative results in $23 \%$ of the patients, half of whom had unstable cervical spine injuries. ${ }^{20}$ Plain radiographs have also been shown to 
have a low sensitivity in confused patients. In a study to determine the usefulness of radiographs in patients with a low clinical suspicion of cervical spine fracture, Lange et al found an incidence rate of $0.0 \%$ for cervical spine fractures on plain x-ray imaging and an overall positivity rate of $6.4 \%$ for cervical spine Computed Tomography $(\mathrm{CT}){ }^{21} \mathrm{CT}$ scanner were previously referred to as the "doughnut of death" due to delays in acquiring images. They have supplanted plain radiographs for the imaging of suspected spinal injuries due to their accuracy, ability to produce images in every spatial plane, cost-effectiveness and speed. ${ }^{22-24}$ A CT scan of the cervical spine is the gold standard imaging modality for patients with a suspected cervical spine injury. ${ }^{25}$

Although MRI scans are not indicated for cervical spine clearance, they are a useful adjunct in patients whose injuries are not well delineated using a CT scan They are more sensitive to soft tissue injuries and are able to detect disruptions to the Discoligamentous Complex (DLC). Pourtaheri et al found that cervical MRI data included additional clinically useful information in $48 \%$ of cases, led to a change in management in $39 \%$, and a decision for surgery in patients previously assumed to be non-operative in $24 \% .{ }^{26}$ The drawbacks of MRI imaging are that they are expensive, time-consuming, and are a logistic challenge for patients who have monitoring equipment in-situ. ${ }^{27}$ Figure 2 shows an algorithm for the initial assessment and management of a suspected CSI in the Emergency Department.

\section{Spinal Stability}

As defined by White and Panjabi, spinal stability is the spine's ability under physiologic loads to limit patterns of

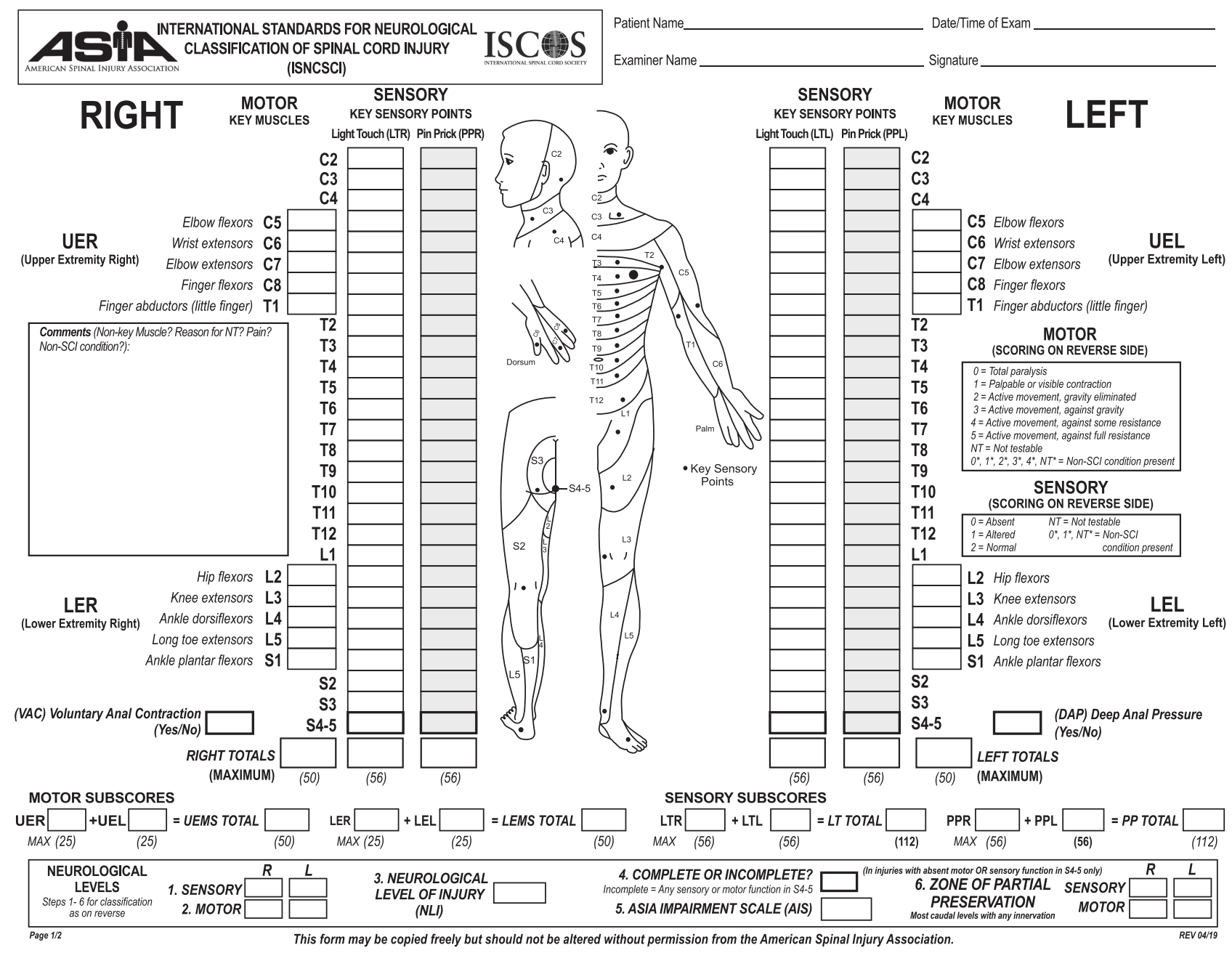

Figure I Continue. 


\section{Muscle Function Grading}

$0=$ Total paralysis

1 = Palpable or visible contraction

2 = Active movement, full range of motion (ROM) with gravity eliminated

3 = Active movement, full ROM against gravity

4 = Active movement, full ROM against gravity and moderate resistance in a muscle specific position

$\mathbf{5}=$ (Normal) active movement, full ROM against gravity and full resistance in a functional muscle position expected from an otherwise unimpaired person

NT = Not testable (i.e. due to immobilization, severe pain such that the patient cannot be graded, amputation of limb, or contracture of $>50 \%$ of the normal ROM)

$0^{*}, 1^{*}, 2^{*}, 3^{*}, 4^{*}, N T^{*}=$ Non-SCl condition present ${ }^{a}$

\section{Sensory Grading}

$0=$ Absent 1 = Altered, either decreased/impaired sensation or hypersensitivity

$2=$ Normal $\mathrm{NT}=$ Not testable

$0^{*}, 1^{*}, \mathrm{NT}^{*}=$ Non-SCl condition present ${ }^{\mathrm{a}}$

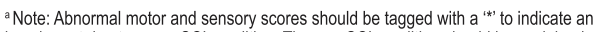
impairment due to a non-SCl condition. The non- $\mathrm{SCl}$ condition should be explained in the com due to a non-scl condion. The non-s

When to Test Non-Key Muscles:

\begin{tabular}{|c|c|}
\hline Movement & Root level \\
\hline $\begin{array}{l}\text { Shoulder: Flexion, extension, adbuction, adduction, } \\
\text { internal and external rotation } \\
\text { Elbow: Supination }\end{array}$ & C5 \\
\hline $\begin{array}{l}\text { Elbow: Pronation } \\
\text { Wrist: Flexion }\end{array}$ & C6 \\
\hline $\begin{array}{l}\text { Finger: Flexion at proximal joint, extension } \\
\text { Thumb: Flexion, extension and abduction in plane of thumb }\end{array}$ & C7 \\
\hline $\begin{array}{l}\text { Finger: Flexion at MCP joint } \\
\text { Thumb: Opposition, adduction and abduction } \\
\text { perpendicular to palm }\end{array}$ & C8 \\
\hline Finger: Abduction of the index finger & $\mathrm{T1}$ \\
\hline Hip: Adduction & L2 \\
\hline Hip: External rotation & L3 \\
\hline $\begin{array}{l}\text { Hip: Extension, abduction, internal rotation } \\
\text { Knee: Flexion } \\
\text { Ankle: Inversion and eversion } \\
\text { Toe: MP and IP extension }\end{array}$ & L4 \\
\hline Hallux and Toe: DIP and PIP flexion and abduction & L5 \\
\hline Hallux: Adduction & S1 \\
\hline
\end{tabular}

ASIA Impairment Scale (AIS)

$A=$ Complete. No sensory or motor function is preserve in the sacral segments $\$ 4-5$

B = Sensory Incomplete. Sensory but not motor function is preserved below the neurological level and includes the sacral segments S4-5 (light touch or pin prick at S4-5 or deep anal pressure) AND no motor function is preserved more than three levels below the motor level on either side of the body.

$\mathbf{C}=$ Motor Incomplete. Motor function is preserved at the most caudal sacral segments for voluntary anal contraction (VAC) OR the patient meets the criteria for sensory incomplete status (sensory function preserved at the mos caudal sacral segments S4-5 by LT, PP or DAP), and has some sparing of motor function more than three levels below the ipsilateral motor level on either side of the body. (This includes key or non-key muscle functions to determine motor incomplete status.) For AIS C - less than half of key muscle functions below the single NLI have a muscle grade $\geq 3$

D $=$ Motor Incomplete. Motor incomplete status as defined above, with at least half (half or more) of key muscle functions below the single NLI having a muscle grade $\geq 3$.

$E=$ Normal. If sensation and motor function as tested with $E=$ NoICSCI. If sensation and motor function as tested with patient had prior deficits, then the AIS grade is $\mathrm{E}$. Someone without an initial $\mathrm{SCI}$ does not receive an AIS grade.

Using ND: To document the sensory, motor and NLI levels, the ASIA Impairment Scale grade, and/or the zone of partial preservation (ZPP) when they are unable to be determined based on the examination results.

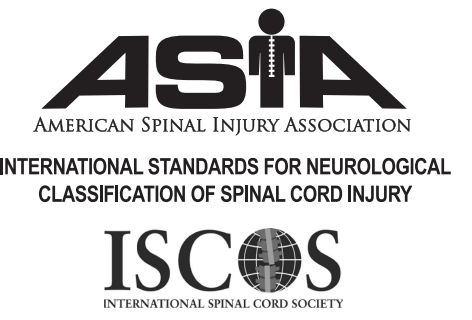

Page 2/2

\section{Steps in Classification}

The following order is recommended for determining the classification of individuals with $\mathrm{SCl}$.

1. Determine sensory levels for right and left sides. The sensory level is the most caudal, intact dermatome for both pin prick and light touch sensation.

2. Determine motor levels for right and left sides. Defined by the lowest key muscle function that has a grade of at least 3 (on supine testing), providing the key muscle functions represented by segments above that level are judged to be intact (graded as a 5). Note: in regions where there is no myotome to test, the motor level is presumed to be the same as the sensory level if testable motor function above that level is also normal.

3. Determine the neurological level of injury (NLI). This refers to the most caudal segment of the cord with intact sensation and antigravity ( 3 or more) muscle function strength, provided that there is norm (intact) sensory and motor function rostrally respectively. The NLI is the most cephalad of the sensory and motor levels determined in steps 1 and 2 .

4. Determine whether the injury is Complete or Incomplete.

(i.e. absence or presence of sacral sparing)

If voluntary anal contraction $=$ No AND all S4-5 sensory scores $=0$

AND deep anal pressure $=$ No, then injury is Complete .

Otherwise, injury is Incomplete.

5. Determine ASIA Impairment Scale (AIS) Grade. Is injury Complete? If YES, AIS=A

NO $\downarrow$

Is injury Motor Complete? If YES, AIS=B

NO (No=voluntary anal contraction OR motor function more than three levels below the motor level on a given side, if the patient has sensory incomplete classification)

Are at least half (half or more) of the key muscles below the neurological level of injury graded 3 or better?

$$
\begin{gathered}
\text { NO } \downarrow \\
\text { AIS=C }
\end{gathered} \quad \text { YES } \downarrow
$$

If sensation and motor function is normal in all segments, AIS=E Note: AIS E is used in follow-up testing when an individual with a documented $\mathrm{SCl}$ has recovered normal function. If at initial testing no deficits are found, the individual is neurologically intact and the ASIA Impairment Scale does not apply.

6. Determine the zone of partial preservation (ZPP). The ZPP is used only in injuries with absent motor (no VAC) OR sensory function (no DAP, no LT and no PP sensation) in the lowest sacral segments S4-5, and refers to those dermatomes and myotomes caudal to the sensory and motor levels that remain partially innervated. With sacral sparing of sensory function, the sensory ZPP is not applicable and therefore "NA" is recorded in the block of the worksheet. Accordingly, if VAC is present the motor ZPP is not applicable and is noted as "NA".

Figure I The International Standards for Neurological Classification of Spinal Cord Injury. Reprinted from American Spinal Injury Association: International Standards for Neurological Classification of Spinal Cord Injury, revised 2019; Richmond, VA. Available from: https://asia-spinalinjury.org/international-standards-neurological-classificationsci-isncsci-worksheet/. ${ }^{28}$

displacement so as not to damage or irritate the spinal cord and nerve roots, and also, to prevent incapacitating deformity or pain due to structural changes. Instability (acute or chronic) refers to an excessive spine displacement that would result in a neurologic deficit, deformity, or pain. ${ }^{29}$

In his landmark work, Panjabi very elegantly conceptualized the stability of the spine to be dependent on the harmonious functioning of three subsystems: the active musculoskeletal subsystem (muscles and tendons), the passive musculoskeletal subsystem (discs, ligaments, joints and soft tissue) and the neural and feedback subsystem (force and motion transducers, nerves). ${ }^{30}$ Therefore, it follows that a dysfunction of any of these systems following trauma can lead to instability of the spine.
The Cervical spine can be anatomically divided into the axial (Occipito-cervical junction and the atlantoaxial spine $\mathrm{C} 1-\mathrm{C} 2)$ and the subaxial (C3-C7) segments. The axial spine accounts for most flexion-extension and rotational movements of the cervical spine and compared to the subaxial spine, relies considerably on ligamentous support for stability. Bogduk and colleagues described the cervical spine as consisting of four discrete functional and anatomical units: the cradle (atlas), the axis, the root (C2-C3 junction) and the column (C3-C7), each contributing distinctively to the biomechanics of the cervical spine. ${ }^{31}$

Several clinical classifications of spinal injuries have been evolved over the last few decades to facilitate accurate and clear communication between clinicians. Older classifications have been more mechanistic, dependent on the 


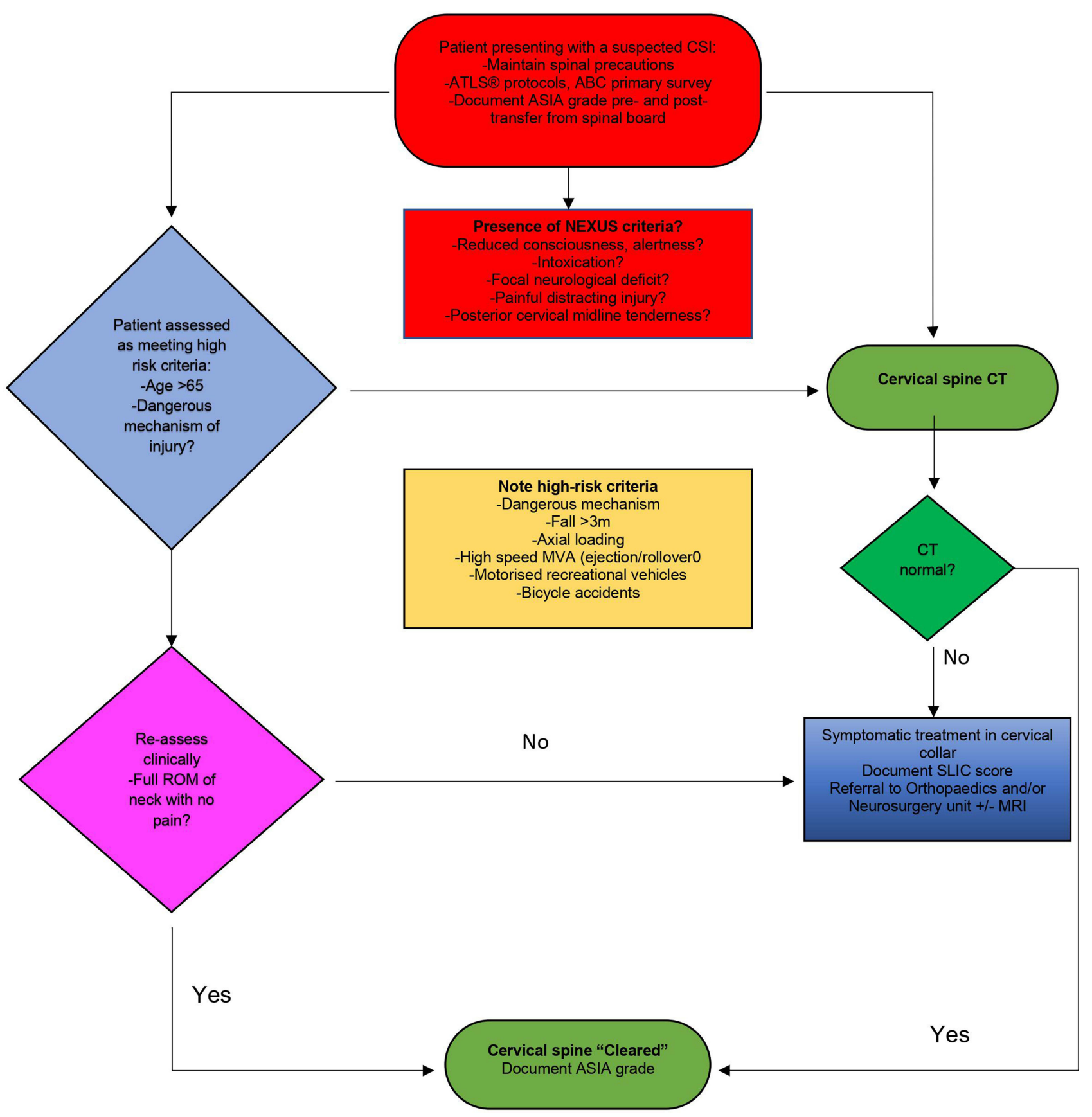

Figure 2 An algorithm for the management of suspected CSI in the Emergency Department.

injury's radiographic morphology and lacking in severity grade, hence, unable to predict stability and outcome. ${ }^{31}$ More current classification systems consider the patient's global picture, have more validity, reliability, and clinical consequence. They can accurately guide treatment and determine potential outcomes.

\section{Upper Cervical Spine Injuries Atlanto-Occipital Dislocations (AOD)}

This is a highly unstable devastating injury arising from the osseoligamentous disruption of all the major stabilizers of the atlanto-occipital joint: alar ligaments, the tectorial membrane, and the atlanto-occipital joint capsule. 


\section{Occipital Condyle Fractures}

This injury generally occurs unilaterally secondary to axial trauma. Historically classified before the advent of $\mathrm{CT}$ and MRI imaging by Anderson and Montesano and more recently by Tuli et al. ${ }^{29,32}$

\section{Atlas Fractures}

Isolated fractures of the $\mathrm{C} 1$ vertebrae are quite easily diagnosed on plain films. The atlas is a bony ring, implying that fractures at this level almost always involve at least two points. Jefferson et al described a characteristic 4-point burst fracture morphology. CT imaging is usually required to classify an atlas fracture as a stable or unstable burst fracture. The presence of a bony avulsion of the Transverse Atlantal Ligament (TAL) is usually the indicator of potential instability.

\section{Odontoid Fractures}

Odontoid fractures account for $20 \%$ of all cervical spine fractures and occur secondary to an avulsion injury involving the apical ligament. ${ }^{33}$ They are stable injuries when they occur in isolation. Anderson and D'Alonzo initially classified odontoid fractures into three types, based on the fracture patterns.

\section{Pars Interarticularis Fractures}

More traditionally referred to as "Hangman's fractures", these injuries are caused by a hyperextension and hyperflexion injury mechanism causing a traumatic spondylolisthesis of $\mathrm{C} 2$ on $\mathrm{C} 3$. The most frequently utilized classification system is the Levine and Edwards modification of the Effendi classification. ${ }^{34}$

\section{Axis Body Fractures}

These are fractures of the $\mathrm{C} 2$ vertebral body.

The AO Spine classification of upper cervical injuries is a modern classification system that aims to simplify and generalize the process of classifying upper cervical injuries by combining all levels from the occiput to the $\mathrm{C} 2-3$ facet joint complex into three anatomic types and then further subdividing according to injury type and presence of neurological signs and/or modifying factors.

Type

- Type 1: Occipital condyle and occipital cervical joint complex injuries

- Type 2: $\mathrm{C} 1$ ring and $\mathrm{C} 1-2$ joint complex injuries

- Type 3: $\mathrm{C} 2$ and $\mathrm{C} 2-3$ joint complex injuries

Injury types (A, B or C)

- A: Bony injury only - considered stable injuries
- B: Tension band injuries - considered potentially unstable injuries

- C: Translation injuries - considered unstable injuries

Neurological signs (N)

- NX: The patient cannot be examined

- N0: No neurological deficits

- N1: Transient neurological injury

- N2: Nerve root injury

- N3: Incomplete spinal cord injury

- N4: Complete spinal cord injury

- +: Continued spinal cord compression

Modifiers (M)

- M1: Injury with significant potential for instability

- M2: Injury at high risk of non-union with nonoperative treatment

- M3:Patient-specific factors affecting treatment (eg, age, smoking status, medical comorbidities, concurrent injuries, or metabolic bone disease)

- M4: Vascular injury or abnormality affecting treatment

\section{Subaxial Cervical Spine Fractures}

The Allen-Ferguson classification of subaxial injuries was one of the historical classifications for subaxial injuries. It divides injuries into six types: compression-flexion, vertical compression, distraction-flexion, compression-extension, distraction-extension, and lateral flexion. More recently, the AO classification and the Subaxial Cervical Spine Classification (SLIC) and severity scale published by Vaccaro et al in 2007 are more widely employed. The SLIC classification system is based on three factors: fracture morphology, neurological status, and the disco-ligamentous complex's integrity (DLC) ${ }^{35}$ It is more frequently employed due to its high intra-rater intraclass correlation and inter-rater intraclass correlation measurements of 0.83 and 0.71 , respectively. ${ }^{36,37}$ The SLIC classifies injuries as follows:

1. Injury morphology:

- No abnormality 0 points

- Compression 1 point

- Burst fracture 2 points

- Distraction 3 points (perched facet joints, hyperextension injuries) 
- Translation or rotation injuries 4 points (facet dislocation, unstable teardrop, or advanced flexion/compression)

2. Discoligamentous complex (DLC) formed by the intervertebral disc, anterior and posterior longitudinal ligaments, interspinous ligaments, facet capsules, and ligamentum flavum:

- Intact 0 points

- Indeterminate 1 point (isolated magnetic resonance imaging signal change or isolated widening of the spinous process)

- Disrupted 2 points (widening of the disc, facet perch or locked).

3. Neurologic status:

- Intact 0 points

- Root injury 1 point

- Complete cord injury 2 points

- Incomplete cord injury 3 points and $(+1)$ continuous cord compression in the setting of neurological deficit.

Injuries with a score $<3$ can be treated conservatively, scores $>5$ are managed surgically, and the managing team's preference for either surgical or conservative treatment is usually indicated for scores of exactly 4 .

Patients suspected of having sustained a cervical fracture should have their clinical history, examination findings, and imaging outcomes integrated by the assessing clinician to guide classification and subsequent management.

\section{Treatment of Cervical Spine Injuries}

The principles of treatment of a spinal injured patient are to:

- Decompress neurological structures

- Prevent or correct segmental collapse and deformity

- Restore normal spinal mechanics

- Avoid and manage complications

- Facilitate early ambulation and rehabilitation

\section{Conservative Treatment}

Until recent advances and developments in the surgical management of spine injuries, non-operative therapy had been the mainstay of treatment of spinal injuries. Despite remarkable innovations and advancements in spine surgery, conservative management still has a role to play, either in the initial stage of injury, later as an adjunct to surgery, or as the definitive treatment of spinal injuries. The non-operative treatment of cervical spine fractures employs the use of traction and ideally external fixation, halo-vests, and cervical braces. Conservative treatment is indicated for the treatment of all fractures that are not dislocated and which are not unstable.

\section{Skeletal Skull Traction}

Skeletal skull traction via skull tongs or a halo ring can be used in cases of facet subluxation/dislocation, burst fractures, and in high cervical fractures to immobilize and realign the cervical spine. ${ }^{38}$ Unilateral or bilateral facet dislocations in an alert patient amenable to serial neurological examinations can be managed definitively by closed reduction with skull traction. The recommendation in closed reduction with traction is to begin with the application of 10 to 15 pound weights and then 5 to 10 pounds for each level of injury added incrementally with serial neurologic exams. ${ }^{39}$ There is, however, a potential for worsening of disc protrusion during closed reduction, therefore, in patients who are obtunded or unable to cooperate with serial neurological testing, an MRI scan should be acquired before attempts at closed reduction. Skull tractions are generally poorly tolerated by patients and can be a cause of morbidity.

\section{Cervical Braces}

Cervical collars and cervicothoracic orthoses are indicated for the definitive treatment of patients with stable lower cervical injuries or as an adjunct post-operatively in patients with questionable fixation. Collars are more comfortable for patients when compared to skull traction techniques but tend to allow significant motion of the spine. Johnson and colleagues described three broad categories of cervical orthoses: collars, poster braces, cervicothoracic braces, and halo vests. ${ }^{40}$ Types of collars include soft collars, semi-rigid collars and rigid collars. Examples of semi-rigid collars are Philadelphia collars, Miami collars, Aspen collar, and the Malibu brace. Rigid collars are employed in the prehospital transport of trauma patients with suspected cervical spine injuries.

Cervicothoracic braces extend over the trunk and are indicated for stable injuries and lower cervical injuries. Poster braces are like cervicothoracic orthoses and control the head through padded mandibular and occipital supports with metal uprights and flexible straps that connect the 
anterior and posterior components. Generally, increasing the working length of cervical orthosis improves their ability to restrict rotatory and flexion motion in the lower cervical spine but have no effect on lateral bending as well as flexionextension in the upper cervical spine. Compression type fractures with no posterior ligaments or capsule involvement can be managed non-operatively in a rigid cervical orthosis.

\section{Halo Vests}

Halos vests are employed when rigid fixation of an unstable cervical spine injury is needed and can be used for definitive treatment of injuries. The halo is connected to the trunk by metal bars which may be attached to a plastic body vest. Hyperextension injuries in the elderly following a fall in the presence of degenerative kyphotic and spondylotic cervical spinesand type 3 odontoid fractures can generally be managed non-operatively in a halo vest.

\section{Pharmacologic Treatment}

From a pharmaceutical perspective, only high-dose Methylprednisolone Sodium Succinate (MPSS) showed modest success in the landmark National Acute Spinal Cord Injury Study (NASCIS) trial, with all other drugs failing to show any benefits in clinical efficacy trials. ${ }^{41}$ MPSS functions as an immunosuppressant and anti-inflammatory There have however been concerns raised over the efficacy and safety of MPSS in patients with an acute SCI. ${ }^{42}$ Fehlings et al, following a systematic review on the use of MPSS in acute SCI, suggested not offering 24-hour infusions of highdose MPSS to patients with an acute SCI after 8 hours and not offering 48-hour infusions to acute SCI patients . ${ }^{43}$ The NICE guidelines in the UK explicitly recommend not using MPSS in acute SCI treatment. ${ }^{44}$ Some potential pharmacological treatments at various stages of development and evaluation include the antibiotic Minocycline, Riluzole, Cethrin, and Premarin to name a few.

\section{Surgical Treatment}

Indications for surgical management of SCI are:

- Unstable injuries.

- Progressive neurological deterioration.

- For early mobilization in neurologically compromised patient.

- In patients with a high incidence of late complications, eg, kyphosis of $30^{\circ}$ or loss of height of more than $50 \%$.
The immediate aims of surgery are to realign the spine, decompress neural elements, and provide mechanical stability. Surgical options for treating subaxial cervical injuries include anterior decompression (discectomy/corpectomy) and fusion, posterior stabilization with or without decompression and a circumferential approach to the spine that combines both anterior and posterior approaches. ${ }^{45}$ Surgical stabilization should also be considered in patients who are still unable to mobilize with appropriate bracing. ${ }^{46}$

\section{Timing of Surgery}

The widely accepted 2-hit theory of spinal cord injury describes an initial primary injury resulting from trauma causing lacerations or intramedullary haematoma formation and a subsequent cascade of secondary injury mechanisms that exacerbate the degree of neural tissue destruction. $^{34}$ Wilson et al strongly recommended the early application of surgical decompression and spinal stabilization (within 24 hours) of SCI when medically feasible based on available data that showed secondary injuries of the spinal cord could be attenuated by decompressive surgery. ${ }^{46,47}$ There is a consensus amongst spine surgeons on the early surgical management of patients with an incomplete or progressing SCI, while early surgery for patients with complete injuries is still controversial. The Surgical Timing in Acute Spinal Cord Injury Study (STASCIS), a multicentre international study that recruited patients between the age of 16 to 80 with a cervical SCI, showed a $19.8 \% \geq 2$ ASIA grade improvement in patients who had early surgery (14.2 \pm 5.2 hours) compared to an $8.8 \%$ rate of improvement in patients who had late surgery $(48.3 \pm 29.3$ hours $) .{ }^{48,49}$

\section{Anterior or Posterior Approach}

The decision on the best approach is based primarily on the morphology of the injury. The anterior approach to the spine, first described by Robinson and Smith in their 1935 landmark paper, is best employed when adequate decompression with removing a vertebral body is required. ${ }^{50}$ There is usually minor muscle splitting in this approach, and so it is considered to be more favourable for patients post-operatively. Upper cervical spine injuries that lend themselves to an anterior approach include type 2 odontoid peg fractures via direct screw fixation of the dislocated fragment under traction, Jefferson fractures, and Hangman fractures.

The posterior approach is excellent for alignment and stability, and ensures anatomic reduction of facet joints. It confers better biomechanical stability in cadaver studies 


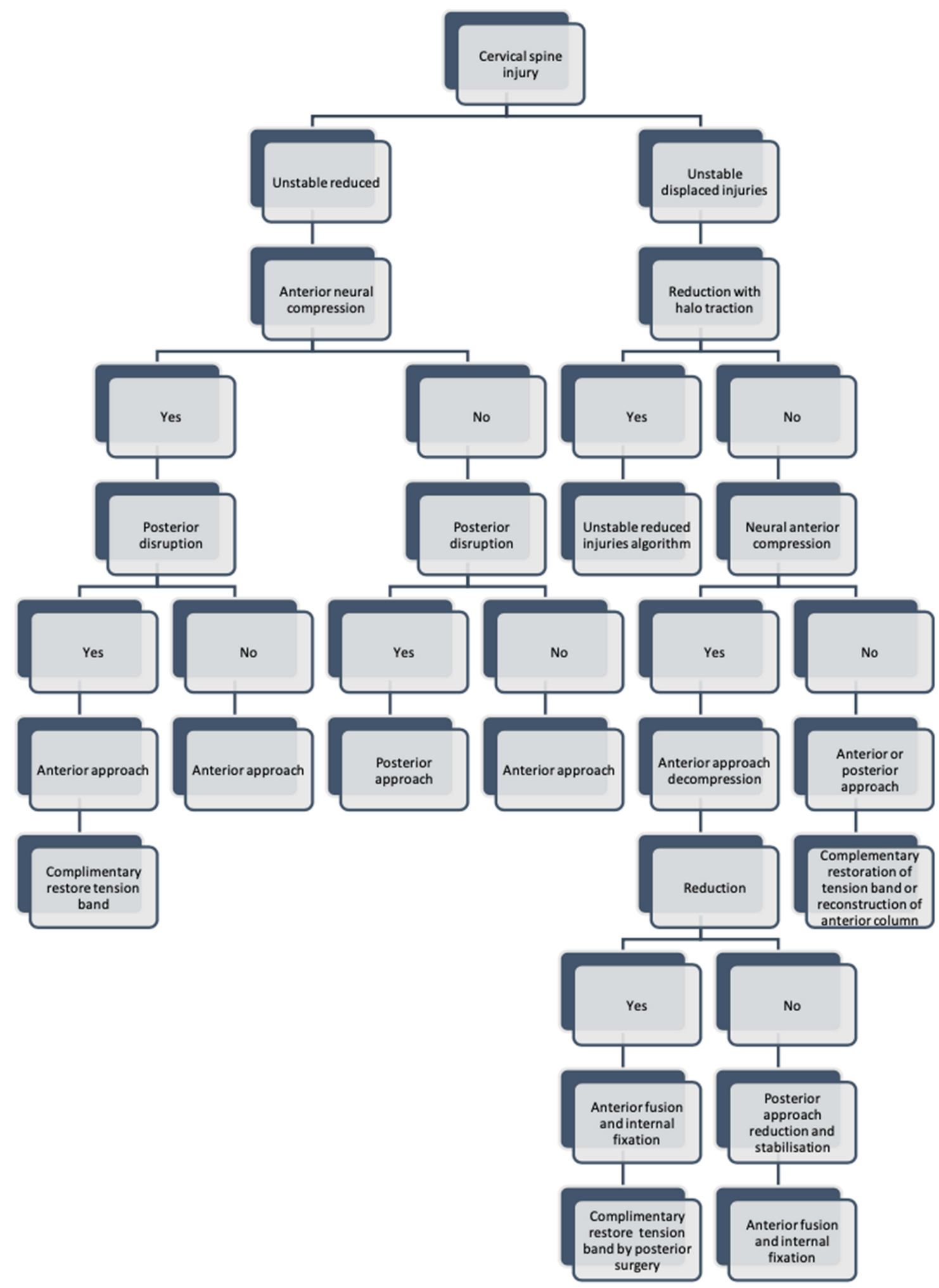

Figure 3 Algorithm for the surgical management of cervical spine injuries. ${ }^{52}$ 
and is used for C2 lateral mass screw placement and pars screw fixations in the upper cervical spine. There is, however, no evidence that supports the use of one approach over the other. Brodke et al reported no significant differences in fusion rates, neurologic recovery, or long-term outcomes between the two approaches. ${ }^{51}$ Highly unstable fracture dislocation/subluxation require a combined approach for spinal decompression, anterior column height restoration, and reconstruction of the posterior complex.

Complications following an anterior approach include: oesophageal injury, injury to the recurrent or superior laryngeal nerves, injuries to the vertebral and carotid arteries. Other complications are an ossified posterior longitudinal ligament (PLL), adjacent segment degeneration (ASD), and pseudoarthrosis. Screw malpositioning leading to spinal cord and nerve root injuries and post laminectomy kyphosis are some complications of posterior surgery. Rare complications following surgery include post-operative nerve injuries, commonly C5 and C8-T1 nerve palsies, Horner's syndrome, Parsonage-Turner Syndrome (PTS), and surgical site infections. Figure 3 shows the standard algorithm for the management of cervical spine injuries. ${ }^{52}$

\section{Conclusion}

A cervical spine injury, although uncommon, is a catastrophic event and can lead to long-term disability. Evaluating patients with a suspected CSI requires a high index of suspicion, careful clinical and radiological evaluation, and an individualized treatment plan. Treatment aims to halt SCI progression and stabilize the spine to allow rehabilitation of the patient. While conservative management had been the mainstay of treatment, recent advances in surgical techniques and more favourable outcomes have tilted the scale towards more aggressive surgical interventions.

\section{Ethics Approval}

No ethics approval was required for this review.

\section{Author Contributions}

IO conceptualized this review and wrote the first draft of manuscript. KM and DB contributed to the literature review, study design, data extraction and critically reviewed the final manuscript. The first draft of the manuscript was written by IO with contributions from all authors. All authors reviewed and agreed on all versions of the article before submission, during revision, the final version accepted for publication, and any significant changes introduced at the proofing stage.
All authors agree to take responsibility and be accountable for the contents of the article.

\section{Funding}

No funding was received for conducting this study.

\section{Disclosure}

The authors report no conflicts of interest in this work.

\section{References}

1. Crowl AC, Kang JD. Cervical spine. In: Clinical Sports Medicine. Elsevier Inc; 2006:143-149. doi:10.1016/B978-032302588-1.50018$\mathrm{X}$

2. Bostock J, Buckley J, Burden D, et al. National clinical guideline centre spinal injury: assessment and initial management spinal injury assessment: assessment and imaging for spinal injury spinal injury assessment contents; 2015.

3. Milby AH, Halpern CH, Guo W, Stein SC. Prevalence of cervical spinal injury in trauma. Neurosurg Focus. 2008;25(5):E10. doi:10.3171/FOC.2008.25.11.E10

4. Torlincasi AM, Waseem M. Cervical injury. StatPearls Publishing; 2019. Available from: http://www.ncbi.nlm.nih.gov/pubmed/ 28846253. Accessed January 31, 2021.

5. Shafafy R, Valsamis EM, Luck J, et al. Predictors of mortality in the elderly patient with a fracture of the odontoid process. Bone Joint $J$. 2019;101-B(3):253-259. doi:10.1302/0301-620X.101B3.BJJ-20181004.R1

6. Uche EO, Nwankwo OE, Okorie E, Nnezianya I. Cervical spine injury: a ten-year multicenter analysis of evolution of care and risk factors for poor outcome in southeast Nigeria. Niger J Clin Pract. 2015;18(2):203-208. doi:10.4103/1119-3077.151042

7. Rief M, Zoidl P, Zajic P, et al. Atlanto-occipital dislocation in a patient presenting with out-of-hospital cardiac arrest: a case report and literature review. J Med Case Rep. 2019;13(1):1-6. doi:10.1186/ s13256-018-1926-2

8. Cusick JF, Yoganandan N. Biomechanics of the cervical spine 4: major injuries. Clin Biomech. 2002;17(1):1-20. doi:10.1016/S02680033(01)00101-2

9. Anderson PA, Gugala Z, Lindsey RW, Schoenfeld AJ, Harris MB. Clearing the cervical spine in the blunt trauma patient. JAAOS - J Am Acad Orthop Surg. 2010;18(3):149-159.

10. BOAST. Boast 2: spinal clearance in the trauma patient; 2008. Available from: https://www.boa.ac.uk/resources/boast-2-pdf.html. Accessed February 2, 2021.

11. Eismont FJ, Currier BL, McGuire RA. Cervical spine and spinal cord injuries: recognition and treatment. Instr Course Lect. 2004;53:341-358

12. Perry SD, McLellan B, Mcllroy WE, Maki BE, Schwartz M, Fernie GR. The efficacy of head immobilization techniques during simulated vehicle motion. Spine. 1999;24(17):1839-1844. doi:10.1097/00007632-199909010-00014

13. Chandler DR, Nemejc C, Adkins RH, Waters RL. Emergency cervical-spine immobilization. Ann Emerg Med. 1992;21 (10):1185-1188. doi:10.1016/S0196-0644(05)81743-3

14. Sheerin F, de Frein R. The occipital and sacral pressures experienced by healthy volunteers under spinal immobilization: a trial of three surfaces. $J$ Emerg Nurs. 2007;33(5):447-450. doi:10.1016/j. jen.2006.11.004

15. Roberts TT, Leonard GR, Capela DJ. Classifications in Brief: American Spinal Injury Association (ASIA) Impairment Scale. Clin Orthop Relat Res. 2017;475(5):1499. doi:10.1007/S11999016-5133-4 
16. American Spinal Injury Association. Standards for neurological classification of spinal injured patients; 1982. Available from: https:// asia-spinalinjury.org/international-standards-neurologicalclassification-sci-isncsci-worksheet/. Accessed February 4, 2021.

17. Frankel HL, Hancock DO, Hyslop G, et al. The value of postural reduction in the initial management of closed injuries of the spine with paraplegia and tetraplegia. Paraplegia. 1969;7(3):179-192. doi:10.1038/sc.1969.30

18. Ackland H, Cameron P. Cervical spine: assessment following trauma. Aust Fam Physician. 2012;41(4):196-200.

19. Hoffman JR, Mower WR, Wolfson AB, Todd KH, Zucker MI. Validity of a set of clinical criteria to rule out injury to the cervical spine in patients with blunt trauma. $N$ Engl J Med. 2000;343 (2):94-99. doi:10.1056/nejm200007133430203

20. Izzo R, Guarnieri G, Guglielmi G, Muto M. Biomechanics of the spine. Part II: spinal instability. Eur J Radiol. 2013;82(1):127-138. doi:10.1016/j.ejrad.2012.07.023

21. Lange BB, Penkar P, Binder WD, Novelline RA. Are cervical spine radiograph examinations useful in patients with low clinical suspicion of cervical spine fracture? An experience with 254 cases. Emerg Radiol. 2010;17(3):191-193. doi:10.1007/s10140-009-0830-x

22. Daffner RH. Cervical radiography for trauma patients: a time-effective technique? Am J Roentgenol. 2000;175 (5):1309-1311. doi:10.2214/ajr.175.5.1751309

23. Blackmore CC, Ramsey SD, Mann FA, Deyo RA. Cervical spine screening with CT in trauma patients: a cost-effectiveness analysis. Radiology. 1999;212(1):117-125. doi:10.1148/radiology.212.1.r99j108117

24. Nuñez DB, Ahmad AA, Coin CG, et al. Clearing the cervical spine in multiple trauma victims: a time-effective protocol using helical computed tomography. Emerg Radiol. 1994;1(6):273-278. doi:10.1007/ BF02614949

25. Daffner RH, Hackney DB. ACR appropriateness criteria ${ }^{\circledR}$ on suspected spine trauma. J Am Coll Radiol. 2007;4(11):762-775. doi:10.1016/j.jacr.2007.08.006

26. Pourtaheri S, Emami A, Sinha K, et al. The role of magnetic resonance imaging in acute cervical spine fractures. Spine J. 2014;14 (11):2546-2553. doi:10.1016/j.spinee.2013.10.052

27. Patel MB, Humble SS, Cullinane DC, et al. Cervical spine collar clearance in the obtunded adult blunt trauma patient: a systematic review and practice management guideline from the Eastern Association for the Surgery of Trauma. J Trauma Acute Care Surg. 2015;78(2):430-441. doi:10.1097/TA.0000000000000503

28. The American Spinal Injury Association. International Standards for Neurological Classification of SCI (ISNCSCI) worksheet-American Spinal Injury Association. Published 2021. Available form: https:// asia-spinalinjury.org/international-standards-neurological-classifica tion-sci-isncsci-worksheet/. Accessed September 1, 2021.

29. McKelvy PL. Clinical biomechanics of the spine. Phys Ther. 1979;59 (8):1045-1047. doi:10.1093/ptj/59.8.1045a

30. Panjabi MM. The stabilizing system of the spine. Part I. Function, dysfunction, adaptation, and enhancement. j spinal disorder. 1992;5(4):383389; discussion 397. doi:10.1097/00002517-199212000-00001.

31. Bogduk N, Mercer S. Biomechanics of the cervical spine. I: normal kinematics. Clin Biomech. 2000;15(9):633-648. doi:10.1016/S02680033(00)00034-6

32. Tuli S, Tator CH, Fehlings MG, Mackay M. Occipital condyle fractures. Neurosurgery. 1997;41(2):368-377. doi:10.1097/00006 123-199708000-00006

33. Smith HE, Kerr SM, Fehlings MG, et al. Trends in epidemiology and management of type II odontoid fractures: 20-year experience at a model system spine injury tertiary referral center. $J$ Spinal Disord Tech. 2010;23(8):501-505. doi:10.1097/BSD.0b013e3181cc43c7

34. Wilson JR, Fehlings MG. Emerging approaches to the surgical management of acute traumatic spinal cord injury. Neurotherapeutics. 2011;8(2):187-194. doi:10.1007/s13311-011-0027-3
35. Joaquim A, Patel A, Vaccaro A. Cervical injuries scored according to the subaxial injury classification system: an analysis of the literature. J Craniovertebr Junction Spine. 2014;5(2):65-70. doi:10.4103/09748237.139200

36. Vaccaro AR, Hulbert RJ, Patel AA, et al. The subaxial cervical spine injury classification system. Spine. 2007;32(21):2365-2374. doi:10.1097/BRS.0b013e3181557b92

37. Stone A, Bransford R, Lee M, et al. Reliability of classification systems for subaxial cervical injuries. Evid Based Spine Care J. 2010;1(03):19-26. doi:10.1055/s-0030-1267064

38. Lauweryns P. Role of conservative treatment of cervical spine injuries. Eur Spine J. 2010;19:23-26. doi:10.1007/s00586-0091116-4

39. Kwon BK, Vaccaro AR, Grauer JN, Fisher CG, Dvorak MF. Subaxial cervical spine trauma. JAAOS - J Am Acad Orthop Surg. 2006;14 (2):78-89.

40. Johnson RM, Hart DL, Simmons EF, Ramsby GR, Southwick WO. Cervical orthoses. A study comparing their effectiveness in restricting cervical motion in normal subjects. J Bone Jt Surg - Ser A. 1977;59(3):332-339. doi:10.2106/00004623-197759030-00007

41. Bracken MB, Shepard MJ, Collins WF, et al. A randomized, controlled trial of methylprednisolone or naloxone in the treatment of acute spinal-cord injury. $N$ Engl J Med. 1990;322(20):1405-1411. doi:10.1056/nejm199005173222001

42. Qian T, Campagnolo D, Kirshblum S. High-dose methylprednisolone may do more harm for spinal cord injury. Med Hypotheses. 2000;55 (5):452-453. doi:10.1054/mehy.2000.1165

43. Fehlings MG, Wilson JR, Tetreault LA, et al. A clinical practice guideline for the management of patients with acute spinal cord injury: recommendations on the use of methylprednisolone sodium succinate. Global Spine J. 2017;7(3_supplement):203S-211S. doi:10.1177/2192568217703085

44. National Institute for Health and Care Excellence (NICE). Do not use the methylprednisolone, nimodipine or naloxone to provide neuroprotection and prevention of secondary deterioration, in the acute stage after acute traumatic spinal cord injury. NICE; Available from: https://www. nice.org.uk/donotdo/do-not-use-The-methylprednisolone-nimodipineor-naloxone-to-provide-neuroprotection-and-prevention-of-secondarydeterioration-in-The-acute-stage-after-acute-traumatic-spinal-cordinjury. Accessed July 30, 2021.

45. Zaveri G, Das G. Management of sub-axial cervical spine injuries. Indian J Orthop. 2017;51:633-652. doi:10.4103/ortho.IJOrtho_19 2_16

46. O'dowd JK. Basic principles of management for cervical spine trauma. Eur Spine J. 2010;19:18-22. doi:10.1007/s00586-009-1118-2

47. Carlson GD, Gorden CD, Oliff HS, Pillai JJ, LaManna JC. Sustained spinal cord compression: part I: time-dependent effect on long-term pathophysiology. J Bone Joint Surg Am. 2003;85(1):86-94. doi:10.2106/00004623-200301000-00014

48. Joaquim AF, Patel AA. Subaxial cervical spine trauma: evaluation and surgical decision-making. Global Spine J. 2013;4(1):63-69. doi:10.1055/S-0033-1356764

49. Fehlings MG, Vaccaro A, Wilson JR, et al. Early versus delayed decompression for traumatic cervical spinal cord injury: results of the surgical timing in acute spinal cord injury study (STASCIS). PLoS One. 2012;7:2. doi:10.1371/JOURNAL.PONE.0032037

50. Robinson RA, Smith GW. Anterolateral cervical disc removal and interbody fusion for cervical disc syndrome. SAS J. 2010;1(4):34-35. doi:10.1016/J.ESAS.2010.01.003

51. Brodke DS, Anderson PA, Newell DW, Grady MS, Chapman JR. Comparison of anterior and posterior approaches in cervical spinal cord injuries. J Spinal Disord Tech. 2003;16(3):229-235. doi:10.1097/00024720-200306000-00001

52. Aebi M, Webb J. The spine. In: Müller ME, editor. Manual of internal fixation 3. Berlin: Springer;. 1991. 


\section{Publish your work in this journal}

Orthopedic Research and Reviews is an international, peer-reviewed, open access journal that focusing on the patho-physiology of the musculoskeletal system, trauma, surgery and other corrective interventions to restore mobility and function. Advances in new technologies, materials, techniques and pharmacological agents are particularly welcome. The manuscript management system is completely online and includes a very quick and fair peer-review system, which is all easy to use. Visit http://www.dovepress.com/testimonials.php to read real quotes from published authors. 